AMPS 2020: Advances in Production Management Systems:

Towards Smart and Digital Manufacturing

IFIP Advances in Information and Communication Technology, Volume 592,

30 August - 3 September 2020, Novi Sad, Serbia, pp. 649-657

DOI:10.1007\%2F978-3-030-57997-5_75

\title{
Digital Technology Enablers for Resilient and Customer Driven Food Value Chains
}

\author{
Christos Emmanouilidis ${ }^{1[0000-0003-4335-6915]}$ and Serafim Bakalis ${ }^{20000-0002-5593-4498]}$ \\ ${ }^{1}$ Cranfield University, Cranfield, MK43 OAL, UK \\ ${ }^{2}$ University of Nottingham, Nottingham, NG7 2RD UK \\ ${ }^{1}$ christosemecranfield.ac.uk
}

\begin{abstract}
Food production chains have to respond to disrupted global markets and dynamic customer demands. They are coming under pressure to move from a supply to a demand-driven business model. The inherent difficulties in the lifecycle management of food products, their perishable nature, the volatility in global and regional supplier and customer markets, and the mix of objective and subjective drivers of customer demand and satisfaction, compose a challenging food production landscape. Businesses need to navigate through dynamically evolving operational risks and ensure targeted performance in terms of supply chain resilience and agility, as well as transparency and product assurance. While the industrial transition to digitalised and automated food production chains is seen as a response to such challenges, the contribution of industry 4.0 technology enablers towards this aim is not sufficiently well understood. This paper outlines the key features of high performing food production chains and performs a mapping between them and enabling technologies. As digitalisation initiatives gain priority, such mapping can help with the prioritisation of technology enablers on delivering key aspects of high performing food production chains.
\end{abstract}

Keywords: Food production; Customer-driven models; Industry 4.0.

\section{Introduction}

Food value chains involve wide range and versatile processes with a very diverse range of stakeholders situated all the way from primary and manufacturing producers to the end customer. At the low value end lie commodity products, characterised by high production and supply volumes but with tight profitability margins. At the high value end it is increasingly common to identify prime products and services associated with them targeting niche markets or individual customers [1]. A wide range of products and services populate the space between the two ends. Supply chain agility and resilience [2][3][4], customer orientation [5][6], as well as traceability [7][8] and transparency [9] are among the most important considerations when managing production and in particular food value chains. Extensive research and several surveys dealing with the digital transformation of supply chains have been published [9][10][11][12][13]. Such transformation is associated with dynamic and evolving business models [14][15] but the extent to which different technology enablers of digital transformation contribute to 
innovative and in particular to consumer - driven food value chains is less well explored. This paper contributes to filling this gap by (a) outlining the key challenges of consumer - driven food value chains; (b) discussing the main characteristics of demand-driven food chains; (c) mapping the extent to which different enabling technologies for digitalized food production chains contribute to addressing the challenges and to the desired characteristics of demand-driven food value chains.

\section{Visual Analytics on Relevant Literature}

A literature search for journal articles has been performed in both the Web of Science (WoS) core collection and Scopus on "food production" and "supply chain" aimed at identifying the key concepts that have been targeted in the last 3 years in these areas. The intention was not to perform a detailed literature analysis but to inform a higherlevel meta-analysis on the interrelationship between key challenges, requirements, and potential solution enablers. To this end, the obtained results were analysed through the graph network bibliometric visualisation tool VOSviewer (VOSviewer.com). The tool was employed to build network graphs of terms employed in article titles and abstracts. The key visualization features are determined by scores and weights and are visualised with bubbles and connectors. High scores correspond to more frequently used terms and are depicted with larger bubbles. Thicker connectors correspond to more frequent co-occurrence of terms. Trimming out weak connections and infrequent terms while not allowing significant cluster fragmentation, WoS produced two main clusters, one "red cluster" contained terms relevant to the overall "food ecosystem" (Fig. 1).

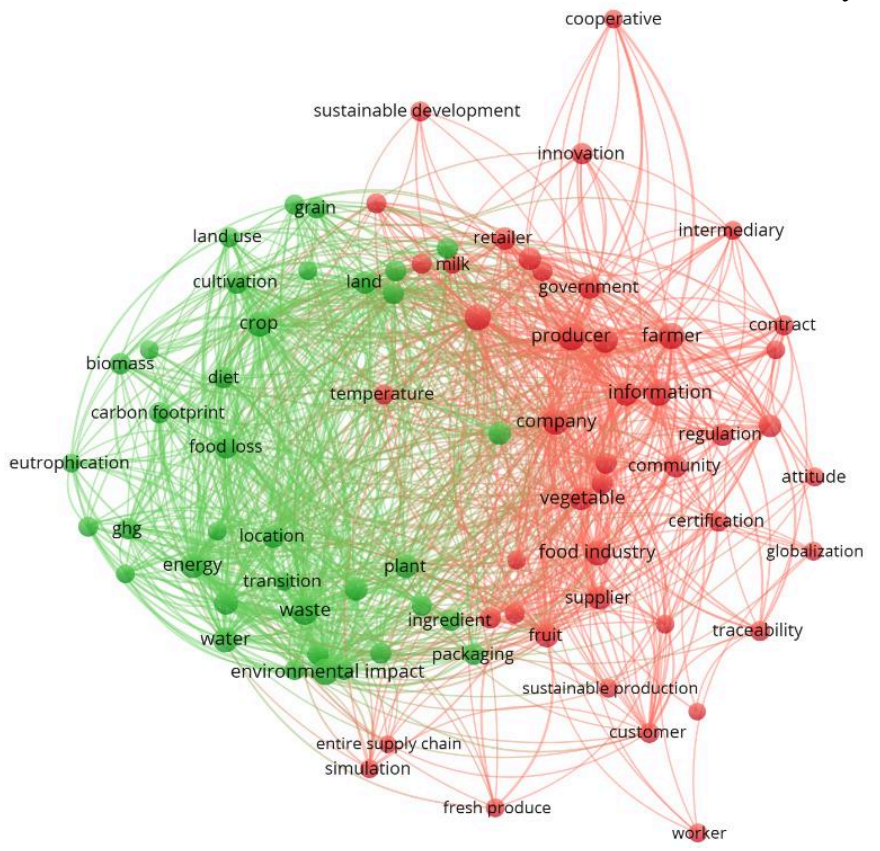

Fig. 1. WoS Visual Analysis of literature 
The green cluster was mostly relevant to resources and sustainability. There was very limited evidence of Industry 4.0 technology enablers in the terms. The Scopus picture has similarities with WoS and displays three main clusters (Fig. 2). The green one is largely about resources and sustainability. Instead of a single food ecosystem cluster two clusters are formed: one relevant to the stakeholders of the production ecosystem and associated processes and characteristics; and one relevant to biological aspects, including health, risk, and ingredients.

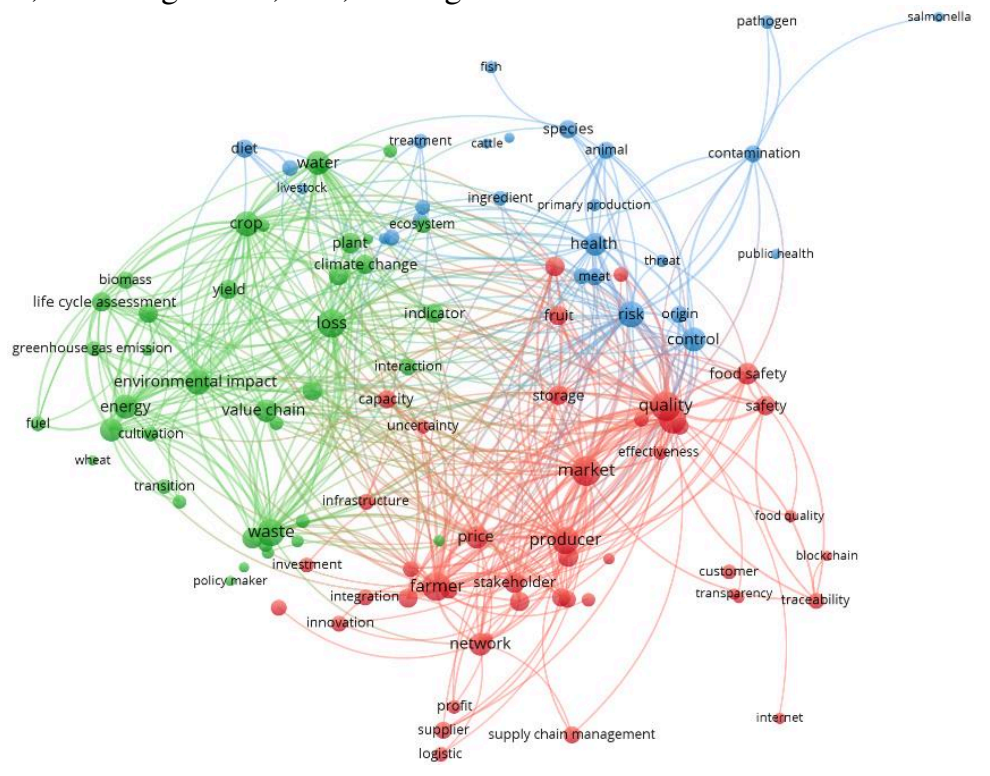

Fig. 2. Scopus Visual Analysis of Food Production and Supply Chain literature

This reflects the somewhat different disciplines covered by the two databases, with Scopus covering more engineering and technology, compared to WoS. However, this less significant compared to the observation that in none of the two cases can one identify any strong presence of digital enabling technologies. Both cases avoided explicitly including digitalisation terms in the search so as to explore whether such terms are already prevalent in the literature, rather than directing the search towards them. This indicates that relevant research still has to catch up with employing such technologies.

\section{Characteristics of Resilient Customer Driven Food Chains}

Successful and sustainable food value chains with strong customer orientation are expected to exhibit some key characteristics, which are largely considered to fall under the broad categories of (i) food ecosystem; and (ii) performance, encompassing:

Food ecosystem and market agility and resilience.

- Food ecosystem stakeholders integration [16][17]

- Business models and innovation [16] [5] [18] [19] [14] [15]

- Sustainability [5] [20] 
- Resilience / agility (logistics routing, suppliers, returns, last mile, local chain) [2] [5] [19] [3]

- Personalised customer experience, prosumers, and behavioural changes [21]

Performance, quality and safety assurance.

- Performance and risk management (suppliers, speed, costs, inventories) [22]

- Transparency [23] and traceability [7][24]

- Product assurance and compliance [25][26][27][28][7]

While the above is not a complete list of key characteristics, it contains some of the most recognizable ingredients that can lead to high-performing food value chains. The birds-eye view of related literature indicates a clear need to link such characteristics with current and emerging technology enablers for digitalized food value chains. The present paper focuses on several such technology enablers:

- Human Interaction Technologies [13][10][6]

- Machine Learning \& Data Analytics [29] [7]

- Internet of Things (with one or more of sensing, identification, communication, computing) [10] [30] [31] [24] [12] [22] [28] [7] [32]

- Security, Safety \& Trust Technologies and Architectures (including hyperledger architectures) [28] [33] [34] [35] [36] [37] [32]

- System Integration [26] [32]

- Semantics, Context, Information Management, and Interoperability [38]

- Connectivity (Physical Layer, Networking, Application Layer) [39]

- Augmented / Virtual Reality (AR/VR) [13]

- Simulation [40][41]

- Cloud - based platforms [42]

- Automation and Robotics [10]

- Advanced / smart materials and packaging (includes embedded/printed electronics) [27][43][13][44]

Table 1. Mapping between technology enablers and food chain characteristics

\begin{tabular}{|c|c|c|c|c|c|c|c|c|}
\hline & \begin{tabular}{|l} 
Ecosystem / \\
Stakeholders \\
Integration
\end{tabular} & \begin{tabular}{|l} 
Personalised \\
Customer \\
Experience \& \\
Engagement
\end{tabular} & \begin{tabular}{|l|} 
Performance \\
and Risk \\
Management \\
(suppliers, \\
speed, costs, \\
inventories)
\end{tabular} & \begin{tabular}{|l} 
Business \\
models
\end{tabular} & Sustainability & \begin{tabular}{|l|} 
Resilience and \\
Agility: logistics, \\
routing, suppliers, \\
returns, last mile
\end{tabular} & $\begin{array}{l}\text { Transparency } \\
\text { and traceability }\end{array}$ & \begin{tabular}{|l|} 
Product \\
assurance \\
and \\
compliance
\end{tabular} \\
\hline Human Interaction Technologies & $x$ & $x x x$ & $x$ & & $x$ & $\mathrm{x}$ & $x x$ & \\
\hline Machine Learning - Al - Analytics & & $x x x$ & $x x x$ & $\mathrm{x}$ & $\mathrm{x}$ & $x x$ & $x x$ & $\mathrm{x}$ \\
\hline $\begin{array}{l}\text { Internet of Things (with one or more } \\
\text { of sensing, identification, } \\
\text { communication, computing) }\end{array}$ & $x x$ & $x x x$ & $x x x$ & $x x$ & $x x$ & $x x x$ & $x x x$ & $x x x$ \\
\hline $\begin{array}{l}\text { Security \& Trust Technologies and } \\
\text { Architectures }\end{array}$ & $x x x$ & $x x x$ & $x x$ & $x x x$ & $x$ & $x x$ & $x x x$ & $x x x$ \\
\hline System Integration & $x x x$ & $x x$ & $x X X$ & $x x x$ & $x x x$ & $x x x$ & $x x$ & $\mathrm{x}$ \\
\hline \multicolumn{9}{|l|}{ Connectivity } \\
\hline Physical Layer & $x x$ & $x x$ & $x x$ & $\mathrm{x}$ & $x x$ & $x x x$ & $x x x$ & $x x x$ \\
\hline Networking & $x x x$ & $x X x$ & $x x x$ & $x x$ & $x x x$ & $x x x$ & $x x x$ & $x x x$ \\
\hline Application Layer & $x \mathrm{XX}$ & $x X x$ & $x x$ & $x X x$ & $x x$ & $x x x$ & $x x$ & $x x$ \\
\hline $\begin{array}{l}\text { Interoperability, including } \\
\text { semantics and context } \\
\text { information management }\end{array}$ & $x x x$ & 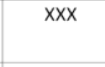 & $\mathrm{x}$ & $x$ & $x x$ & $\mathrm{x}$ & $\mathrm{x}$ & $\mathrm{xx}$ \\
\hline AR/VR & $\mathrm{x}$ & $x x x$ & $x$ & & & & $x x$ & $x x$ \\
\hline Simulation & & & $x x x$ & $x x$ & $x x x$ & $x x x$ & & $\mathrm{x}$ \\
\hline Cloud - based platforms & $x x x$ & $x x$ & $x x x$ & $x x x$ & $\mathrm{x}$ & $x x x$ & $x x x$ & $x x$ \\
\hline Automation and robotics & $x x x$ & $x x x$ & $x x x$ & $x x x$ & $x$ & $x x x$ & $x x x$ & $x x x$ \\
\hline $\begin{array}{l}\text { Advanced / smart materials and } \\
\text { packaging (includes } \\
\text { embedded/printed electronics) }\end{array}$ & $x$ & $x x$ & $x x x$ & $x x x$ & $x x x$ & $x X x$ & $x X x$ & $x x x$ \\
\hline
\end{tabular}


All the above are typically associated with Industry 4.0. The last one can be considered as part of automation and robotics, but is listed separately to indicate the critical role it has within internal and external logistics, and retailing. Table 1 maps the extent to which the above technologies contribute to delivering the key characteristics. Food ecosystem integration heavily depends on overall system integration, interoperability and cross-layer connectivity and requires cloud-based platforms. Security and trust technologies are of paramount importance, while automation and robotics are key operational technologies that enable production and logistics workflows. Ensuring customer engagement is complex and relies to a significant extent on involving nearly all listed technology enablers, starting from human interaction ones. Performance and risk management, as well as resilience and agility requires the inclusion of higher added value enablers, such as AI, IoT, simulation, and advanced packaging, on top of others. Business models are enabled by application layer connectivity, integration, cloud platforms for stakeholders integration, as well by automation technologies and smart packaging. Simulation is key for sustainability regarding the design perspective, while operational delivery requires integration, connectivity, and advanced packing to inform consumer behaviour. IoT is key for transparency, traceability, and product assurance, together with security \& trust, connectivity, and cloud platforms, integrating also automation technologies and smart packaging for transparent and efficient workflows. Nonetheless, the mapping, currently based on literature and own judgement, requires a more systematic analysis and this needs to include also consumer behavioural studies.

\section{Conclusion}

Food value chains are increasingly driven by changing individual customer demands and are required to respond to highly disruptive market changes. Facing such challenges, food production ecosystems are undergoing digital transformation. Although relevant literature is rich with respect to the emerging characteristics of future resilient food value chains, as well as regarding the use of digitalisation enablers, the contribution of such enablers towards consumer oriented or driven food value chains and their agile and resilient characteristics is less well established. Customer - driven products specifically depend on more complex food value chains, compared to conventional supply models and their dependence on efficient end-to-end digitization is evident. This paper analysed current literature in this area and proposed a mapping between relevant technology enablers that support such digital transformation. While the mapping takes into account current literature together with own judgement to produce a rated mapping of technology enablers contribution, more systematic research, which includes empirical findings is needed to establish its validity and indeed apply appropriate adjustments and extensions. Such a mapping is a valuable tool towards devising a model for prioritising digitization interventions for food value supply chains.

\section{References}

1. Dreyer, H.C., Strandhagen, J.O., Hvolby, H.H., Romsdal, A., Alfnes, E.: Supply chain 
strategies for speciality foods: A norwegian case study. Prod. Plan. Control. 27, 878-893 (2016). https://doi.org/10.1080/09537287.2016.1156779.

2. Stone, J., Rahimifard, S.: Resilience in agri-food supply chains: a critical analysis of the literature and synthesis of a novel framework. Supply Chain Manag. 23, 207-238 (2018). https://doi.org/10.1108/SCM-06-2017-0201.

3. Ali, I., Nagalingam, S., Gurd, B.: A resilience model for cold chain logistics of perishable products. Int. J. Logist. Manag. 29, 922-941 (2018). https://doi.org/10.1108/IJLM-06-20170147.

4. Rotz, S., Fraser, E.D.G.: Resilience and the industrial food system: analyzing the impacts of agricultural industrialization on food system vulnerability. J. Environ. Stud. Sci. 5, 459-473 (2015). https://doi.org/10.1007/s13412-015-0277-1.

5. Todorovic, V., Maslaric, M., Bojic, S., Jokic, M., Mircetic, D., Nikolicic, S.: Solutions for more sustainable distribution in the short food supply chains. Sustain. 10, (2018). https://doi.org/10.3390/su10103481.

6. Giannikas, V., McFarlane, D., Strachan, J.: Towards the deployment of customer orientation: A case study in third-party logistics. Comput. Ind. 104, 75-87 (2019). https://doi.org/10.1016/j.compind.2018.10.005.

7. Alfian, G., Syafrudin, M., Farooq, U., Ma'arif, M.R., Syaekhoni, M.A., Fitriyani, N.L., Lee, J., Rhee, J.: Improving efficiency of RFID-based traceability system for perishable food by utilizing IoT sensors and machine learning model. Food Control. 110, (2020). https://doi.org/10.1016/j.foodcont.2019.107016.

8. Badia-Melis, R., Mishra, P., Ruiz-García, L.: Food traceability: New trends and recent advances. A review. Food Control. 57, 393-401 (2015). https://doi.org/10.1016/j.foodcont.2015.05.005.

9. Astill, J., Dara, R.A., Campbell, M., Farber, J.M., Fraser, E.D.G., Sharif, S., Yada, R.Y.: Transparency in food supply chains: A review of enabling technology solutions. Trends Food Sci. Technol. 91, 240-247 (2019). https://doi.org/10.1016/j.tifs.2019.07.024.

10. Miranda, J., Ponce, P., Molina, A., Wright, P.: Sensing, smart and sustainable technologies for Agri-Food 4.0. Comput. Ind. 108, 21-36 (2019). https://doi.org/10.1016/j.compind.2019.02.002.

11. Büyüközkan, G., Göçer, F.: Digital Supply Chain: Literature review and a proposed framework for future research. Comput. Ind. 97, 157-177 (2018). https://doi.org/10.1016/j.compind.2018.02.010.

12. Lezoche, M., Panetto, H.H., Kacprzyk, J., Hernandez, J.E., Alemany Díaz, M.M.E., Alemany, M., Lezoche, M., Hernandez, J.E., Alemany, M., Panetto, H.H., Kacprzyk, J., Lezoche, M., Hernández, J.E., Eva, M., Diaz, A., Panetto, H.H., Kacprzyk, J.: Agri-food 4.0: A survey of the Supply Chains and Technologies for the Future Agriculture. Comput. Ind. 117, 103187 (2020). https://doi.org/10.1016/j.compind.2020.103187.

13. Vanderroost, M., Ragaert, P., Verwaeren, J., De Meulenaer, B., De Baets, B., Devlieghere, F.: The digitization of a food package's life cycle: Existing and emerging computer systems in the logistics and post-logistics phase. Comput. Ind. 87, 15-30 (2017). https://doi.org/10.1016/j.compind.2017.01.004.

14. Spendrup, S., Fernqvist, F.: Innovation in Agri-food Systems - A Systematic Mapping of the Literature. Int. J. Food Syst. Dyn. 10, 402-427 (2019). https://doi.org/10.18461/ijfsd.v10i5.28. 
15. Nosratabadi, S., Mosavi, A., Lakner, Z.: Food supply chain and business model innovation. Foods. 9, (2020). https://doi.org/10.3390/foods9020132.

16. Stancová, K.C., Cavicchi, A.: Smart specialisation and the agri-food system: A European perspective. (2018). https://doi.org/10.1007/978-3-319-91500-5.

17. Zondag, M.M., Mueller, E.F., Ferrin, B.G.: The application of value nets in food supply chains: A multiple case study. Scand. J. Manag. 33, 199-212 (2017). https://doi.org/10.1016/j.scaman.2017.10.002.

18. Utami, H.N., Alamanos, E., Kuznesof, S.: Co-creation Benefits by Re-configuring the Value Network in Creative Agri-food Transformation through the SMEs e-commerce channel: A Business Market Perspective. 98, 63-68 (2019). https://doi.org/10.2991/icot-19.2019.14.

19. Nakandala, D., Lau, H.C.W.: Innovative adoption of hybrid supply chain strategies in urban local fresh food supply chain. Supply Chain Manag. 24, 241-255 (2019). https://doi.org/10.1108/SCM-09-2017-0287.

20. Herrmann, C., Schmidt, C., Kurle, D., Blume, S., Thiede, S.: Sustainability in manufacturing and factories of the future. Int. J. Precis. Eng. Manuf. - Green Technol. 1, 283-292 (2014). https://doi.org/10.1007/s40684-014-0034-z.

21. Kumar, A., Singh, R.K., Modgil, S.: Exploring the relationship between ICT, SCM practices and organizational performance in agri-food supply chain. Benchmarking. 27, 1003-1041 (2020). https://doi.org/10.1108/BIJ-11-2019-0500.

22. Tsang, Y.P., Choy, K.L., Wu, C.H., Ho, G.T.S., Lam, C.H.Y., Koo, P.S.: An Internet of Things (IoT)-based risk monitoring system for managing cold supply chain risks. Ind. Manag. Data Syst. 118, 1432-1462 (2018). https://doi.org/10.1108/IMDS-09-2017-0384.

23. Hsiao, H.I., Huang, K.L.: Time-temperature transparency in the cold chain. Food Control. 64, 181-188 (2016). https://doi.org/10.1016/j.foodcont.2015.12.020.

24. Liu, K.: Research on the Food Safety Supply Chain Traceability Management System Base on the Internet of Things. Int. J. Hybrid Inf. Technol. 8, 25-34 (2015). https://doi.org/10.14257/ijhit.2015.8.6.03.

25. Aung, M.M., Chang, Y.S.: Traceability in a food supply chain: Safety and quality

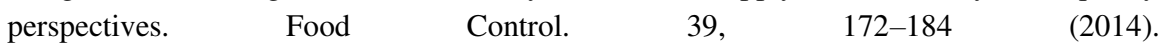
https://doi.org/10.1016/j.foodcont.2013.11.007.

26. Shih, C.W., Wang, C.H.: Integrating wireless sensor networks with statistical quality control to develop a cold chain system in food industries. Comput. Stand. Interfaces. 45, 62-78 (2016). https://doi.org/10.1016/j.csi.2015.12.004.

27. Fang, Z., Zhao, Y., Warner, R.D., Johnson, S.K.: Active and intelligent packaging in meat industry. Trends Food Sci. Technol. 61, 60-71 (2017). https://doi.org/10.1016/j.tifs.2017.01.002.

28. Bouzembrak, Y., Klüche, M., Gavai, A., Marvin, H.J.P.: Internet of Things in food safety: Literature review and a bibliometric analysis. Trends Food Sci. Technol. 94, 54-64 (2019). https://doi.org/10.1016/j.tifs.2019.11.002.

29. Elijah, O., Rahman, T.A., Orikumhi, I., Leow, C.Y., Hindia, M.N.: An Overview of Internet of Things (IoT) and Data Analytics in Agriculture: Benefits and Challenges. IEEE Internet Things J. 5, 3758-3773 (2018). https://doi.org/10.1109/JIOT.2018.2844296.

30. Gialelis, J., Theodorou, G., Paparizos, C.: A low-cost internet of things (IoT) node to support traceability: Logistics use case. ACM Int. Conf. Proceeding Ser. 72-77 (2019). https://doi.org/10.1145/3342428.3342661. 
31. O'Sullivan, M.G.: A Handbook for Sensory and Consumer-Driven New Product Development: Innovative Technologies for the Food and Beverage Industry. Woodhead Publishing (2017).

32. Verdouw, C.N., Robbemond, R.M., Verwaart, T., Wolfert, J., Beulens, A.J.M.: A reference architecture for IoT-based logistic information systems in agri-food supply chains. Enterp. Inf. Syst. 12, 755-779 (2018). https://doi.org/10.1080/17517575.2015.1072643.

33. Mc Carthy, U., Uysal, I., Badia-Melis, R., Mercier, S., O’Donnell, C., Ktenioudaki, A.: Global food security - Issues, challenges and technological solutions. Trends Food Sci. Technol. 77, 11-20 (2018). https://doi.org/10.1016/j.tifs.2018.05.002.

34. Doinea, M., Boja, C., Batagan, L., Toma, C., Popa, M.: Internet of Things Based Systems for Food Safety Management. Inform. Econ. 19, 87-97 (2015). https://doi.org/10.12948/issn14531305/19.1.2015.08.

35. Mondal, S., Wijewardena, K.P., Karuppuswami, S., Kriti, N., Kumar, D., Chahal, P.: Blockchain inspired RFID-based information architecture for food supply chain. IEEE Internet Things J. 6, 5803-5813 (2019). https://doi.org/10.1109/JIOT.2019.2907658.

36. Leng, K., Bi, Y., Jing, L., Fu, H.C., Van Nieuwenhuyse, I.: Research on agricultural supply chain system with double chain architecture based on blockchain technology. Futur. Gener. Comput. Syst. 86, 641-649 (2018). https://doi.org/10.1016/j.future.2018.04.061.

37. Caro, M.P., Ali, M.S., Vecchio, M., Giaffreda, R.: Blockchain-based traceability in AgriFood supply chain management: A practical implementation. 2018 IoT Vert. Top. Summit Agric. - Tuscany, IOT Tuscany 2018. 1-4 (2018). https://doi.org/10.1109/IOTTUSCANY.2018.8373021.

38. Geerts, G.L., O'Leary, D.E.: A supply chain of things: The EAGLET ontology for highly visible supply chains. Decis. Support Syst. 63, 3-22 (2014). https://doi.org/10.1016/j.dss.2013.09.007.

39. Villa-Henriksen, A., Edwards, G.T.C., Pesonen, L.A., Green, O., Sørensen, C.A.G.: Internet of Things in arable farming: Implementation, applications, challenges and potential. Biosyst. Eng. 191, 60-84 (2020). https://doi.org/10.1016/j.biosystemseng.2019.12.013.

40. Raba, D., Juan, A.A., Panadero, J., Bayliss, C., Estrada-Moreno, A.: Combining the Internet of Things with Simulation-Based Optimization to Enhance Logistics in an Agri-Food Supply Chain. Proc. - Winter Simul. Conf. 2019-Decem, 1894-1905 (2019). https://doi.org/10.1109/WSC40007.2019.9004952.

41. Verboven, P., Defraeye, T., Datta, A.K., Nicolai, B.: Digital twins of food process operations: the next step for food process models? Curr. Opin. Food Sci. (2020). https://doi.org/10.1016/j.cofs.2020.03.002.

42. Verdouw, C.N., Wolfert, J., Beulens, A.J.M., Rialland, A.: Virtualization of food supply chains with the internet of things. J. Food Eng. 176, 128-136 (2016). https://doi.org/10.1016/j.jfoodeng.2015.11.009.

43. Ghaani, M., Cozzolino, C.A., Castelli, G., Farris, S.: An overview of the intelligent packaging technologies in the food sector. Trends Food Sci. Technol. 51, 1-11 (2016). https://doi.org/10.1016/j.tifs.2016.02.008.

44. Majid, I., Ahmad Nayik, G., Mohammad Dar, S., Nanda, V.: Novel food packaging technologies: Innovations and future prospective. J. Saudi Soc. Agric. Sci. 17, 454-462 (2018). https://doi.org/10.1016/j.jssas.2016.11.003. 
2020-08-25

\section{Digital technology enablers for resilient and customer driven food value chains}

Emmanouilidis, Christos

Springer

Emmanouilidis C, Bakalis S. (2020) Digital technology enablers for resilient and customer driven food value chains. In: AMPS 2020: Advances in Production Management Systems. Towards Smart and Digital Manufacturing, IFIP Advances in Information and Communication Technology, Volume 592, 30 August - 3 September 2020, Novi Sad, Serbia, pp. 649-657 https://doi.org/10.1007/978-3-030-57997-5_75

Downloaded from Cranfield Library Services E-Repository 